\title{
Fibrin Sealant Patch to Treat Dialysis-Associated Hemorrhagic Pericarditis
}

\author{
Susumu Isoda', Tamizo Kimura², Katsunori Tanaka², Kenji Nishimura², \\ Nozomu Yamanaka ${ }^{2}$, Shin-ichi Taguchi ${ }^{2}$, Norihisa Karube' ${ }^{1}$, Keiji Uchida ${ }^{1}$, Kiyotaka Imoto ${ }^{1}$ \\ ${ }^{1}$ Department of Cardiovascular Surgery, Yokohama City University Medical Center, Yokohama, Japan \\ ${ }^{2}$ Department of Cardiovascular Surgery, National Defense Medical College, Tokorozawa, Japan \\ Email: isoda@yokohama-cu.ac.jp
}

Received 1 February 2015; accepted 21 February 2015; published 28 February 2015

Copyright $@ 2015$ by authors and Scientific Research Publishing Inc.

This work is licensed under the Creative Commons Attribution International License (CC BY).

http://creativecommons.org/licenses/by/4.0/

(c) (i) Open Access

\section{Abstract}

A 73-year-old male patient with a 3-year history of hemodialysis was admitted for the treatment of pericardial effusion. Echocardiography suggested a diagnosis of effusive pericarditis. Pericardiocentesis was performed several times. Six weeks after the admission, the patient developed cardiac tamponade. Surgical pericardiotomy showed the epicardium had a diffuse shaggy and hemorrhagic surface. To control diffuse oozing, fibrin sealant patches (Tachosil; CSL Behring, Tokyo, Japan) were attached to the epicardium. Oozing was then controlled.

\section{Keywords}

Fibrin Sealant Patch, Hemodialysis, Hemorrhage, Pericarditis

\section{Case Report}

A 73-year-old male patient with a 3-year history of hemodialysis became dyspneic. Echocardiography performed at an affiliated hospital suggested a diagnosis of effusive pericarditis. The patient underwent pericardiocentesis. Serous nonbloody pericardial effusion was drained. However, pericardial effusion rapidly recurred, and the patient was transferred to our hospital. Pericaridocentesis using a pig tail catheter revealed that the bloody pericardial effusion was not infective. Malignancy was ruled out. After undergoing five recurrent pericardiocentesis procedures, the patient developed cardiac tamponade and went into cardiopulmonary arrest. Resuscitation was successful and emergent surgery was then performed. Median sternotomy and pericardiotomy revealed a blowing-out of $2 \mathrm{~L}$ of massive effusion and a blood clot. The epicardial surface revealed a diffuse 
shaggy and hemorrhagic surface. To control diffuse oozing, most of the epicardial surface needed to be covered by seven sets of fibrin sealant patches (TachoSil, $9.5 \mathrm{~cm} \times 4.8 \mathrm{~cm}$; CSL Behring, Tokyo, Japan) (Figure 1). After placing the covering, bleeding was mostly controlled, and serous effusion oozing resembling perspiration continued through the fibrin sealant patch. Because we expected that pericardial effusion would continue, we proposed the formation of a peritoneal window from the pericardial space to the peritoneal space. However, his attending physician did not approve this treatment because the physician was concerned about ascites storage.

The pericardial drain was removed on postoperative day 6 and colchicine was started to control pericarditis [1]. The endotracheal tube was removed on postoperative day 8. He was discharged from the intensive care unit on postoperative day 10. His postoperative course was afterward troublesome with respiratory failure and infection, the patient could be discharged from hospital.

\section{Discussion}

The primary causes of cardiac tamponade in uremic pericarditis are pericardial effusion, massive hemorrhage, and collagenization of pericardial exudate [2] [3]. In our patient, pericardial effusion was not bloody initially, but it changed into massive bleeding. This phenomenon is probably explained by two factors: [1] the initial cause of the pericarditis and [2] recurrent hemorrhaging from the granulation tissue that organizes the fibrinous exudate. In addition, the use of anticoagulants in dialyzed patients may have a compound influence in causing hemorrhage [2].

A fibrin sealant patch (TachoSil; CSL Behring, Tokyo, Japan) is a hemostatic material that is widely used in cardiovascular surgery [4] [5]. The situation in our patient was resembled as an oozing rupture after an acute myocardial infarction [6]. Bleeding in the present patient was not a blowout from the cardiac chamber, but the pressure generated by the bloody effusion was apparently greater than the pressure in the right ventricle and greater than the venous pressure because arterioles in the granulation tissue seemed to be diffusely ruptured. We could control the bleeding and cardiac tamponade with fibirin sealant patches, otherwise the bleeding could not be controlled. We recommend using a fibrin sealant patch to control hemorrhagic pericarditis in dialyzed patient, which has not been reported elsewhere.

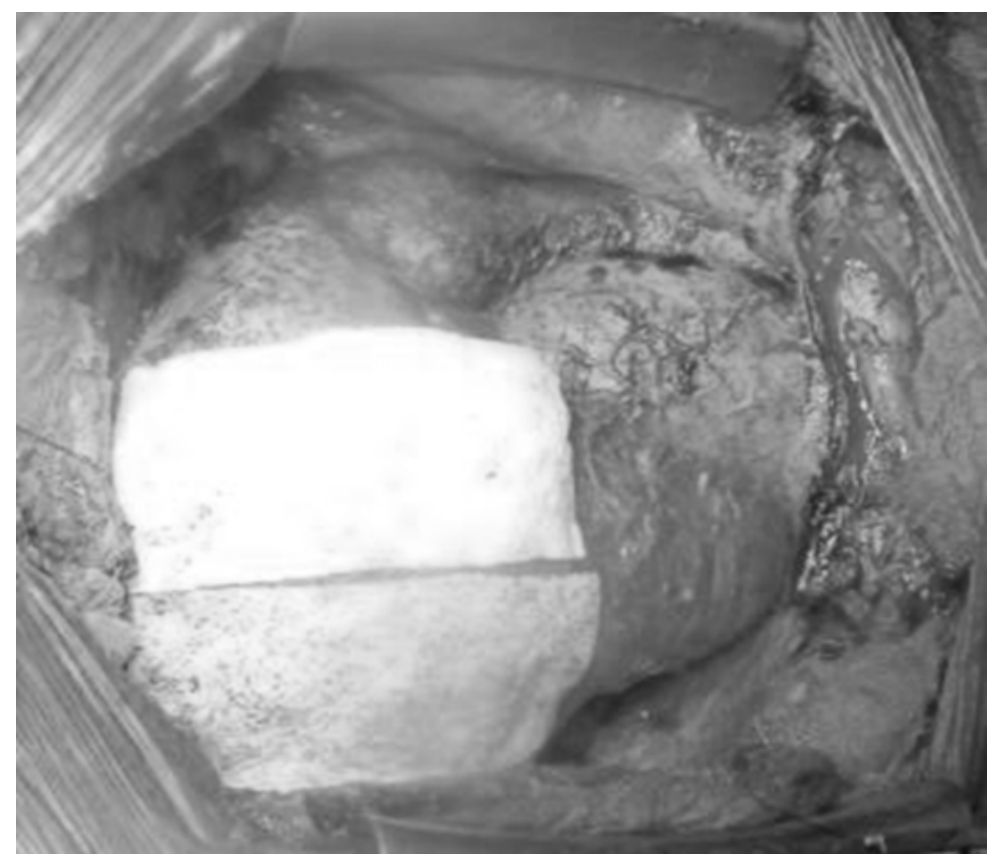

Figure 1. The intraoperative photograph shows two sets of fibrin sealant patches (TachoSil, $9.5 \mathrm{~cm} \times 4.8 \mathrm{~cm}$; CSL Behring, Tokyo, Japan) that are attached to the epicardial surface at the apex to control diffuse oozing. Five more sets of patches were used to cover most of the all epicardial surface to treat otherwise uncontrollable oozing. 


\section{Conflicts of Interest}

Susumu Isoda and all other authors have no conflicts of interest to declare.

\section{References}

[1] Adler, Y., Finkelstein, Y., Guindo, J., et al. (1998) Colchicine Treatment for Recurrent Pericarditis: A Decaide of Experience. Circulation, 97, 2183-2185. http://dx.doi.org/10.1161/01.CIR.97.21.2183

[2] Baldwin, J.J. and Edwards, J.E. (1976) Uremic Pericarditis as a Cause of Cardiac Tamponade. Circulation, 53, 896901. http://dx.doi.org/10.1161/01.CIR.53.5.896

[3] Hoit, B.H. (2002) Management of Effusive and Constrictive Pericardial Heart Disease. Circulation, 105, $2939-2942$. http://dx.doi.org/10.1161/01.CIR.0000019421.07529.C5

[4] Lisy, M., Kahlil, M., Stock, U.A. and Wildhirt, S.M. (2013) Fibrin Sealant Patch for Repair of Acute Type A Aortic Dissection. Journal of Cardiac Surgery, 28, 736-741. http://dx.doi.org/10.1111/jocs.12208

[5] Fiore, A., Grandmougin, D., Maureira, J.P., Elfarra, M., Laurent, N., Andronache, M., Folliruet, T. and Villemot, J.P. (2014) Efficacy of TachoSil ${ }^{\circledR}$ as a Sutureless Hemostatic Patch to Repair a Perforation of the Interventricular Groove during Endocardial Radiofrequency Ablation. The Journal of Cardiovascular Surgery (Torino), 55, 295-298.

[6] Nishizaki, K., Seki, T., Fujii, A., Nishida, Y., Funabiki, M. and Morikawa, Y. (2004) Sutureless Patch Repair for Small Blowout Rupture of the Left Ventricule after Myocardial Infarction. The Japanese Journal of Thoracic and Cardiovascular Surgery, 52, 268-271. http://dx.doi.org/10.1007/s11748-004-0123-y 
Scientific Research Publishing (SCIRP) is one of the largest Open Access journal publishers. It is currently publishing more than 200 open access, online, peer-reviewed journals covering a wide range of academic disciplines. SCIRP serves the worldwide academic communities and contributes to the progress and application of science with its publication.

Other selected journals from SCIRP are listed as below. Submit your manuscript to us via either submit@scirp.org or Online Submission Portal.
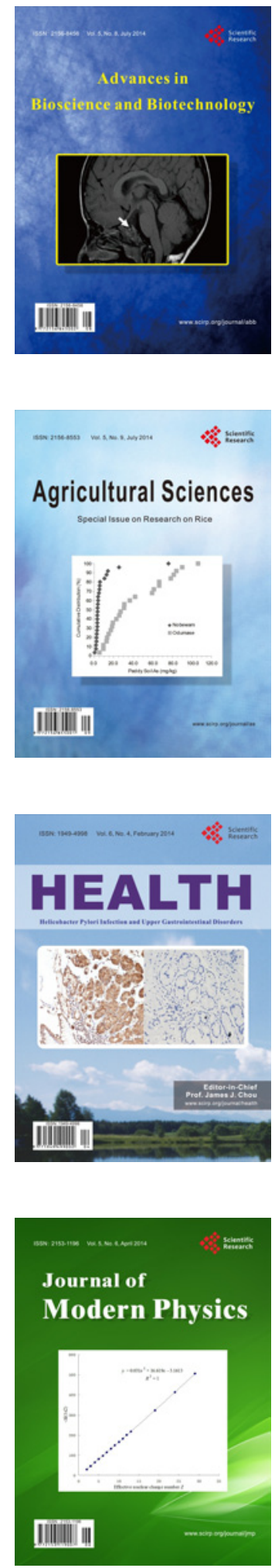
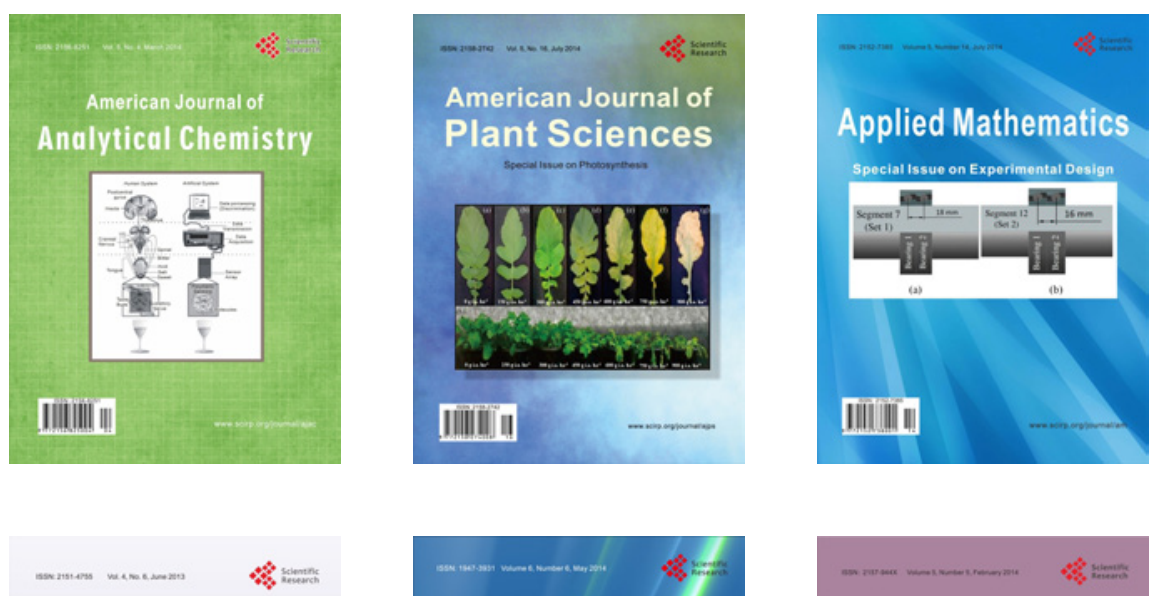

Creative Education
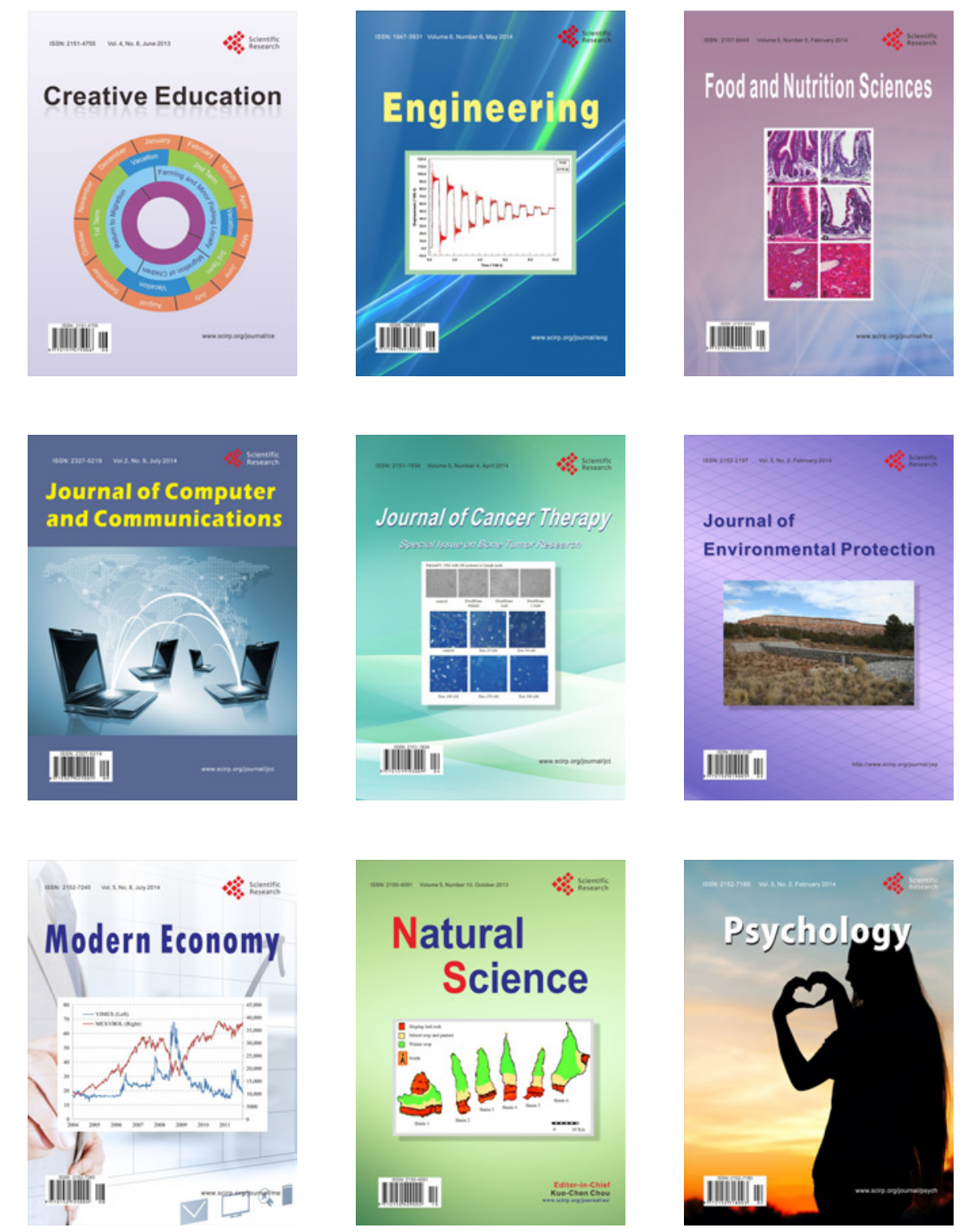